\title{
Case report: clues to the diagnosis of an unsuspected massive levothyroxine overdose
}

\author{
Kirstie M. Allen*; Veronica B. Crawford, MB ChB*; John V. Conaglen, MB ChB, MD*; Marianne S. \\ Elston, $\mathrm{MB}$ ChB, $\mathrm{PhD}^{*}$
}

\section{ABSTRACT}

There is currently little literature pertaining to levothyroxine overdose apart from minor or accidental overdoses in the pediatric population. In particular, there is little information available on how to confidently differentiate levothyroxine overdose from endogenous causes of thyrotoxicosis when there is no history available at the time of assessment.

We report a levothyroxine $(15,800 \mathrm{mcg})$ and citalopram $(2,460 \mathrm{mg})$ overdose in a 55 -year-old woman presenting with seizure and tachycardia in which the diagnosis was not initially suspected. Clinical data, including a long history of treated hypothyroidism and lack of a goiter; and biochemical findings, such as an incompletely suppressed thyroid-stimulating hormone (TSH) level, despite a markedly elevated free thyroxine level $\left(\mathrm{FT}_{4}\right)$, a normal sex hormone-binding globulin level at baseline, and an undetectable thyroglobulin, supported the diagnosis of thyrotoxicosis due to a massive exogenous thyroid hormone overdose. Treatment was given to decrease free triiodothyronine $\left(\mathrm{FT}_{3}\right)$ conversion and increase thyroid hormone clearance with dexamethasone and cholestyramine. The patient made a full recovery.

Levothyroxine overdose can result in subtle symptoms and signs clinically, even when in massive quantities. This can make diagnosis challenging. Biochemical features, such as the pattern of thyroid hormone elevation and thyroglobulin levels, help differentiate exogenous thyroid hormone overdose from endogenous causes of thyrotoxicosis.

\section{RÉSUMÉ}

La documentation sur le surdosage de lévothyroxine est peu abondante, exception faite des surdosages mineurs ou accidentels chez les enfants; plus particulièrement, il manque d'information sur la manière de faire la distinction, en toute confiance, entre le surdosage de lévothyroxine et la thyrotoxicose d'origine endogène, dans les cas d'absence d'antécédents évocateurs au moment de l'évaluation.

Sera exposé ici un cas de surdosage de lévothyroxine (15 $800 \mu \mathrm{g}$ ) et de citalopram (2460 mg) chez une femme de 55 ans, prise de convulsions et de tachycardie, chez qui rien, au point de départ, ne laissait soupçonner le diagnostic. Toutefois, des données d'ordre clinique, notamment des antécédents d'hypothyroïdie traitée de longue date et l'absence de goitre; des résultats d'analyses biochimiques, par exemple la présence de thyréostimuline (TSH) partiellement supprimée malgré un taux nettement élevé de thyroxine libre $\left(\mathrm{T}_{4}\right.$ libre); un taux normal, au départ, de globuline de liaison aux hormones sexuelles et un taux indétectable de thyroglobuline, ont étayé le diagnostic de thyrotoxicose attribuable à un surdosage massif d'hormone thyrö̈dienne d'origine exogène. Le traitement, par la dexaméthasone et la cholestyramine, visait à abaisser la conversion de la triiodothyronine libre $\left(T_{3}\right.$ libre) et à accroître la clairance de l'hormone thyroïdienne. La patiente s'est complètement rétablie.

Le surdosage de lévothyroxine, même massif, peut se manifester par des signes et des symptômes cliniques peu prononcés, d'où la difficulté de poser le diagnostic.

From the *Department of Endocrinology, Waikato Hospital, Waikato Clinical School, University of Auckland, Hamilton, New Zealand.

Correspondence to: Dr. Marianne S. Elston, Department of Endocrinology, Waikato Hospital, Private Bag 3200, Hamilton 3240, New Zealand; Email: Marianne.Elston@waikatodhb.health.nz 
Toutefois, des résultats d'analyses biochimiques, tels que l'élévation du taux d'hormone thyroïdienne et le taux de thyroglobuline, peuvent aider à faire la distinction entre le surdosage d'hormone thyroïdienne d'origine exogène et la thyrotoxicose d'origine endogène.

Keywords: levothyroxine overdose, thyrotoxicosis, hyperthyroxinemia, thyroid crisis, drug overdose

\section{INTRODUCTION}

Levothyroxine is a commonly used medication for hypothyroidism. Despite the large numbers of patients on levothyroxine, there is a surprising paucity of cases of overdose reported in the literature suggesting infrequent overdose with this medication, low toxicity, under-reporting, under-recognition of levothyroxine overdose, or a combination of one or more of these factors.

Chronic thyrotoxicosis is associated with significant morbidity and premature mortality. ${ }^{1}$ A patient who takes an overdose of levothyroxine may be relatively asymptomatic ${ }^{2}$ or may develop the following symptoms: hyperthermia, ${ }^{3}$ cardiac arrhythmias, seizures, ${ }^{4}$ thyroid storm, ${ }^{5}$ and even death. ${ }^{3,6}$ In the 2012 report from the American Association of Poison Control Centers (AAPCC), levothyroxine was one of the drugs ingested in nine fatal overdoses. ${ }^{7}$ All of these fatal overdoses occurred in adults as part of a polydrug overdose. ${ }^{7}$ Outside of the AAPCC data, most published cases are in the pediatric literature and relate to accidental overdose. ${ }^{2,4,5,8-11}$ Adult cases have been reported only rarely and may be accidental, for example, due to ingestion of veterinary tablets. ${ }^{12}$ In the small group of cases reported, the diagnosis is typically evident at presentation, that is, the patient arrives at the hospital already known to have taken an overdose. ${ }^{13-16}$ When there is no information at presentation to support an overdose, diagnostic confusion can occur. This may result in a missed opportunity to identify and initiate treatment for a polydrug overdose and/or result in the administration of unhelpful and potentially harmful therapies if, for example, specific therapy for Graves disease is initiated.

The aims of this case were to describe the biochemical findings diagnostic of exogenous thyroid hormone overdose, as compared to endogenous causes of thyrotoxicosis, and briefly summarize the management of levothyroxine overdose and where it differs to that of Graves disease.

\section{CASE DESCRIPTION}

A 55-year-old woman presented to the emergency department with confusion, dizziness, and vomiting. Shortly after arrival, the patient had a tonic-clonic seizure lasting less than 1 minute. Due to the reduced level of consciousness, no history was available from the patient, but the medication brought in with her by the ambulance staff included levothyroxine and citalopram. From the hospital chart, it was noted that the patient had a past history of Graves disease treated with radioactive iodine in 1993 and had been receiving levothyroxine ( $900 \mathrm{mcg}$ per week). Thyroid function tests were normal 10 months earlier. Family members present at the initial assessment denied that she would ever consider overdose. There was no history of recent weight loss or thyrotoxic symptoms noted by the family members.

On examination, she was afebrile and normotensive with a pulse of 100 beats per minute. A neurological exam revealed a Glasgow Coma Scale (GCS) of 9/15, pupils were equal and reactive to light, but nystagmus was present in all directions. She was hyperreflexive with ankle clonus present. She had no meningism. There was no goiter or thyroid bruit.

A complete blood count, urea and electrolytes, and calcium and glucose were unremarkable. A computed tomography (CT) brain was normal. Thyroid function tests were markedly abnormal (Table 1 ).

The initial working diagnosis was a suspected thyroid storm due to recurrent Graves disease, and she was referred to the endocrine team.

Given the biochemical severity of thyrotoxicosis, despite an incompletely suppressed TSH, long duration of hypothyroidism, lack of recent symptoms and absence of a goiter, a polydrug (including levothyroxine) overdose was suspected. An urgent sex hormone-binding globulin (SHBG) level was within the reference range (see Table 1), and thyroglobulin was undetectable, confirming the clinical suspicion of excess exogenous thyroid hormone ingestion. Treatment was commenced with 


\begin{tabular}{|c|c|c|c|c|c|c|c|c|c|c|}
\hline Analyte & D0 & D1 & D3 & D4 & D5 & D7 & D10 & D12 & D14 & $\mathrm{RR}$ \\
\hline $\mathrm{FT}_{4}$ & $>100$ & $>100$ & $>100$ & $>100$ & 70 & 38 & 22 & 17 & 13 & $12-22 \mathrm{nmol} / \mathrm{L}$ \\
\hline $\mathrm{FT}_{3}$ & 20.2 & 25.5 & 21.9 & 18.2 & 16 & 7.9 & 6 & 4.9 & 4.3 & $3.1-6.8 \mathrm{nmol} / \mathrm{L}$ \\
\hline TSH & 0.21 & 0.05 & $<0.02$ & $<0.02$ & $<0.02$ & $<0.03$ & 0.05 & $<0.03$ & $<0.03$ & $0.27-4.2 \mathrm{mU} / \mathrm{L}$ \\
\hline $\mathrm{SHBG}^{*}$ & 87 & & 110 & & 98 & 130 & 120 & 110 & 97 & $18-114 \mathrm{nmol} / \mathrm{L}$ \\
\hline Thyroglobulin & $<1$ & & & & & & & & & \\
\hline
\end{tabular}

dexamethasone $8 \mathrm{mg}$ daily and cholestyramine $1 \mathrm{~g}$ qid. Cardiac monitoring was performed. Beta-blockade was not given due to a history of asthma.

The patient's GCS normalized within the next 4 hours, and she remained hemodynamically stable with no dysrhythmias. When alert, she admitted an intentional overdose of levothyroxine $(15,800 \mathrm{mcg})$ and citalopram $(2,460 \mathrm{mg})$ approximately 18 hours prior to presentation due to recent severe social stressors.

Cholestyramine was continued until $\mathrm{FT}_{4}$ levels were $<50 \mathrm{pmol} / \mathrm{L}$ with regular monitoring of thyroid tests until the free thyroid hormone levels normalized. TSH receptor antibodies (TRAb) were positive at $4.4 \mathrm{U} / \mathrm{L}$ (normal <1.3 U/L). Following psychiatric assessment, the patient was discharged well on day 5 .

\section{DISCUSSION}

We describe a case of massive levothyroxine overdose associated with co-ingestion of citalopram. Both citalopram and levothyroxine can produce hyperreflexia and clonus. The citalopram was most likely responsible for the seizure because this agent is known to increase seizure risk in doses $>600 \mathrm{mg} .{ }^{17}$ Attributing the seizure to her thyroid dysfunction potentially risked missing the diagnosis of overdose.

\section{Thyroid endocrinology}

Common symptoms and signs of thyrotoxicosis include weight loss, palpitations, nervousness, tremor, tachycardia, goiter, sweating, and thyroid eye signs. ${ }^{18}$ However, elderly patients may present with minimal symptoms (apathetic thyrotoxicosis). ${ }^{18}$ The typical laboratory findings in thyrotoxicosis are of elevated $\mathrm{FT}_{4}$ and $\mathrm{FT}_{3}$ levels with a suppressed TSH due to the negative feedback of free thyroid hormones on the pituitary. This is true for any cause of thyrotoxicosis, including that of excess exogenous thyroid hormone administration with only rare exceptions, for example, secondary hyperthyroidism from a TSH-secreting pituitary tumour. $\mathrm{T}_{3}$ is the active hormone and, in addition to its secretion from the thyroid, is also produced from peripheral conversion of $\mathrm{T}_{4}$. Levothyroxine is a synthetic preparation of $\mathrm{T}_{4}$, which is also converted to $T_{3}$ within the body. Patients receiving adequate levothyroxine replacement should have normal levels of $\mathrm{FT}_{4}, \mathrm{FT}_{3}$, and TSH. Levothyroxine $\left(\mathrm{T}_{4}\right)$ overdose may result in delayed symptoms for several days after overdose because $\mathrm{FT}_{4}$ needs to be converted to the active $\mathrm{FT}_{3} .{ }^{19}$

\section{Diagnosis of levothyroxine overdose}

At initial presentation, this patient had extremely high $\mathrm{FT}_{4}$ levels with an incompletely suppressed TSH level. Although this patient may have had endogenous thyrotoxicosis, such as from a late relapse of her Graves disease, there are a number of factors pointing toward the cause being due to the exogenous thyroid hormone. The most common causes of thyrotoxicosis are Graves disease, toxic multinodular goiter (TMNG), thyroiditis, and excess levothyroxine replacement (acute or chronic). There are key biochemical findings, which can help emergency physicians differentiate between the various diagnoses of thyrotoxicosis, in particular, levothyroxine overdose. Overdose is particularly important to recognize because this may be part of a polydrug overdose requiring specific treatment.

The clinical factors suggestive of exogenous thyroxine being the source of the thyrotoxicosis in this case included the long history of thyroxine use for previously treated Graves disease, the lack of thyrotoxic symptoms or signs noted by the family members, and the lack of a goiter.

The pattern of initial thyroid function tests suggested that an acute levothyroxine overdose was likely. 


\begin{tabular}{|c|c|c|}
\hline Parameter & & Score \\
\hline \multirow[t]{6}{*}{ Temperature $\left({ }^{\circ} \mathrm{C}\right)$} & $37.2-37.7$ & 5 \\
\hline & $37.8-38.2$ & 10 \\
\hline & 38.3-38.8 & 15 \\
\hline & 38.9-39.4 & 20 \\
\hline & 39.4-39.9 & 25 \\
\hline & $>40$ & 30 \\
\hline \multirow[t]{3}{*}{ CNS effects } & Mild (agitation) & 10 \\
\hline & Moderate (delirium/psychosis) & 20 \\
\hline & Severe (seizure/coma) & 30 \\
\hline \multirow[t]{2}{*}{ Gastrointestinal/hepatic dysfunction } & Moderate (diarrhea, nausea, vomiting abdominal pain) & 10 \\
\hline & Severe (unexplained jaundice) & 20 \\
\hline \multicolumn{3}{|l|}{ Cardiac dysfunction } \\
\hline \multirow[t]{5}{*}{ Tachycardia } & $90-109$ & 5 \\
\hline & $110-119$ & 10 \\
\hline & $120-129$ & 15 \\
\hline & $130-139$ & 20 \\
\hline & $\geq 140$ & 25 \\
\hline \multirow[t]{3}{*}{ Congestive heart failure } & Mild (pedal oedema) & 5 \\
\hline & Moderate (bibasal rales) & 10 \\
\hline & Severe (pulmonary oedema) & 15 \\
\hline \multirow[t]{2}{*}{ Atrial fibrillation } & Absent & 0 \\
\hline & Present & 10 \\
\hline \multirow[t]{2}{*}{ Precipitant history } & Negative & 0 \\
\hline & Positive & 10 \\
\hline
\end{tabular}

In particular, despite the very high $\mathrm{FT}_{4}$ value (above the upper limit of the assay), the TSH was incompletely suppressed. The incomplete TSH suppression suggested that the overdose of levothyroxine was likely recent rather than chronic. This was supported by the normal SHBG level that peaked at only day 7 following admission (see Table 1). An urgent thyroglobulin was also performed at admission and was undetectable. Thyroglobulin is a protein specific to thyroid tissue, which can be measured from a peripheral blood sample. An undetectable thyroglobulin (in the absence of interfering antithyroglobulin antibodies) is confirmation that the cause is not due to endogenous thyrotoxicosis. Thyroglobulin levels will also be undetectable in surreptitious chronic thyroid hormone ingestion (thyrotoxicosis factitia). TRAb are not useful to help differentiate recurrent Graves disease from levothyroxine overdose because these may be elevated for many years following radioactive iodine therapy, ${ }^{20}$ as demonstrated in this case.

Thyroid storm is a rare but important condition associated with a high mortality and requires urgent, aggressive therapy. ${ }^{21}$ A scoring system, developed by Burch and Wartofsky, based on abnormalities in the thermoregulatory, central nervous, gastrointestinal, and cardiovascular systems, can be used to help determine whether a patient is likely to have a thyroid storm (Table 2). ${ }^{21}$ This patient did not meet the criteria for the diagnosis due to the absence of fever, significant tachycardia, or other organ involvement. The only potential supporting feature other than thyrotoxicosis was the seizure (likely citalopram-related) and reduced GCS when postictal.

\section{Thyroxine overdose management}

Treatment of levothyroxine overdose should be considered as the following:

1. Decontamination

2. Symptomatic for life-threatening/hemodynamic complications or sympathetic overload

3. Blockade of peripheral conversion

4. Monitoring 


\section{Decontamination}

Criteria are available as to when decontamination and medical treatment following excess thyroxine ingestion are appropriate. ${ }^{19}$ Adults who present with acute ingestion $>5,000 \mathrm{mcg}$ should receive activated charcoal. ${ }^{19}$ There is a limited role for gastric lavage in this setting, except in a very early massive overdose (e.g., $>10,000 \mathrm{mcg}) .{ }^{19}$ In this case, the patient presented approximately 18 hours after an overdose, and so decontamination was not performed.

\section{Symptomatic treatment}

Symptomatic treatment for sympathetic overstimulation (tachycardia, systolic hypertension, widened pulse pressure, or a high cardiac output) with betablockade (or diltiazem if beta-blockade is contraindicated) is recommended. ${ }^{19}$ In addition to the cardiac benefits, propranolol also reduces peripheral conversion of $\mathrm{FT}_{4}$ to the active $\mathrm{FT}_{3}$, which does not occur with selective beta-blockers. Given the history of asthma and the hemodynamic stability, beta-blockade was not given in this case. Beta-blockade can be started at any time point after presentation and the dose tailored to the clinical situation. Hyperthermia should be treated with acetaminophen and cooling cares. ${ }^{19}$ Aspirin should be avoided due to the theoretical risk of increasing free thyroid hormone levels due to displacement from the thyroid hormone-binding proteins. ${ }^{19}$ Use of benzodiazepines can be considered if the patient is severely agitated. ${ }^{19}$

\section{Blockade of peripheral conversion and increasing thyroid hormone clearance}

Dexamethasone can be useful in severe thyrotoxicosis ${ }^{22}$ because it reduces peripheral $\mathrm{FT}_{4}$ to $\mathrm{FT}_{3}$ conversion. Dexamethasone was given, in this case, as the amount of levothyroxine taken was initially unknown, the $\mathrm{FT}_{3}$ was over three times the upper limit of normal, and it was thought that the $\mathrm{FT}_{3}$ level could further increase with the potential for cardiac instability. We would recommend considering corticosteroids in the setting of a massive levothyroxine overdose $(>10,000 \mathrm{mcg})$, especially if the initial $\mathrm{FT}_{4}$ level is above the limit of quantification of the assay or in any patient with associated adrenal insufficiency. Bile acid sequestrants, such as cholestyramine, reduce enterohepatic recycling of thyroxine and have been demonstrated to lower thyroid hormone levels in thyrotoxicosis, ${ }^{23,24}$ including levothyroxine overdose. ${ }^{25}$ Use of these agents in thyrotoxicosis is usually well tolerated and of low toxicity, ${ }^{24}$ so they could be considered in patients who have taken a large overdose, to increase fecal thyroid hormone clearance.

Iopanoic acid and sodium ipodate reduce peripheral conversion of $\mathrm{FT}_{4}$ to $\mathrm{FT}_{3}{ }^{26}$ These agents can be useful for the short-term management of endogenous thyrotoxicosis because they also prevent thyroid hormone secretion acutely. Data on their use in acute levothyroxine overdose are limited to two pediatric case reports where they appeared to be successful. ${ }^{8}$ Routine use of these agents in levothyroxine overdose cannot be recommended due to the limited data available but should be considered in the setting of a thyroid storm. ${ }^{27}$

Hemoperfusion and plasmapheresis have been reported to be successful in removing levothyroxine from the serum. ${ }^{28}$ These methods are not likely to be necessary for most cases of levothyroxine overdose but could be considered in critically ill patients. However, data on the use of these therapies are limited, and not all groups have reported plasmapheresis to be efficacious in this setting. ${ }^{14,29}$

\section{Monitoring}

Depending on the amount ingested, medical observation for at least 3-4 days following overdose should be considered. It is known that the peak thyroxine plasma concentration can occur 2-4 days post-ingestion (due to the long $t_{1 / 2}$ of levothyroxine, approximately 7 days and the need for $\mathrm{T}_{4}$ to be converted to the active $\left.\mathrm{FT}_{3}\right){ }^{19}$ For this reason, close monitoring of vitals (blood pressure, heart rate, respiratory rate, and temperature) is important. Hospital admission may not always be necessary if the patient is stable and psychiatric assessment advises that the patient can be safely discharged, but the amount of levothyroxine ingestion, comorbidities, particularly underlying cardiac disease, and clinical judgment should be used as markers for safe discharge.

\section{Differences in management from endogenous thyrotoxicosis}

Antithyroid drugs, such as methimazole, are usually the mainstay of treatment for Graves disease or TMNG but carry a small but significant risk of life-threatening side effects, such as agranulocytosis and liver dysfunction. ${ }^{30,31}$ Antithyroid drugs are not effective in reducing thyroid hormone levels in exogenous thyroid hormone ingestion because endogenous thyroid hormone production is 
already suppressed. While propylthiouracil also reduces peripheral conversion of free thyroxine $\left(T_{4}\right)$ to free triiodothyronine $\left(\mathrm{T}_{3}\right)$, there are other therapeutic alternatives for this, as described previously. Antithyroid drugs should not be given in the setting of excess exogenous thyroid hormone ingestion. Symptomatic treatment with beta-blockade and consideration of therapies to reduce peripheral conversion and to increase clearance of thyroid hormone are similar for both situations.

\section{TAKE-HOME CLINICAL MESSAGES}

Recognition of levothyroxine overdose is critical for appropriate management.

The diagnosis of levothyroxine overdose may be suggested by the history and examination findings. Biochemical features, such as the pattern of thyroid hormone elevation, SHBG, and thyroglobulin levels, help differentiating exogenous thyroid hormone overdose from endogenous causes of thyrotoxicosis. These tests are readily available from most hospital laboratories.

The ideal management of levothyroxine overdose is patient-dependent. Clinical signs and symptoms are the best indicator for the level of intervention required. Antithyroid drugs should not be given in the setting of exogenous thyroid hormone ingestion.

Competing interests: None declared.

\section{REFERENCES}

1. Brandt F, Green A, Hegedus L, et al. A critical review and meta-analysis of the association between overt hyperthyroidism and mortality. Eur 7 Endocrinol 2011;165(4):491-7.

2. Gorman RL, Chamberlain JM, Rose SR, et al. Massive levothyroxine overdose: high anxiety-low toxicity. Pediatrics 1988;82(4):666-9.

3. Loos V, Das V, Maury E, et al. A thyrotoxicosis outbreak due to dietary pills in Paris. Ther Clin Risk Manag 2008; 4(6):1375-9.

4. Kulig K, Golightly LK, Rumack BH. Levothyroxine overdose associated with seizures in a young child. $7 A M A$ 1985;254(15):2109-10.

5. Majlesi N, Greller HA, McGuigan MA, et al. Thyroid storm after pediatric levothyroxine ingestion. Pediatrics 2010; 126(2):e470-3.

6. Levine JM. A quality improvement study: medication error leading to thyrotoxicosis and death. $7 \mathrm{Am} \mathrm{Med} \mathrm{Dir} \mathrm{Assoc}$ 2004;5(6):410-3.

7. Mowry JB, Spyker DA, Cantilena LR, et al. 2012 Annual report of the American Association of Poison Control
Centers' National Poison Data System (NPDS): 30th annual report. Clin Toxicol 2013;51(10):949-1229.

8. Berkner PD, Starkman H, Person N. Acute L-thyroxine overdose; therapy with sodium ipodate: evaluation of clinical and physiologic parameters. 7 Emerg Med 1991;9(3):129-31.

9. Ho J, Jackson R, Johnson D. Massive levothyroxine ingestion in a pediatric patient: case report and discussion. CFEM 2011;13(3):165-8.

10. Shilo L, Kovatz S, Hadari R, et al. Massive thyroid hormone overdose: kinetics, clinical manifestations and management. Isr Med Assoc 7 2002;4(4):298-9.

11. Singh GK, Winterborn MH. Massive overdose with thyroxine-toxicity and treatment. Eur 7 Pediatr 1991;150(3):217.

12. Narula HS. Accidental thyrotoxicosis caused by inadvertent ingestion of levothyroxine "dog-tabs" by a veterinarian with hypothyroidism. Am 7 Med 2012;125(7):e3.

13. Matthews SJ. Acute thyroxine overdosage: two cases of parasuicide. Ulster Med $\mathscr{f}$ 1993;62(2):170-3.

14. May ME, Mintz PD, Lowry P, et al. Plasmapheresis in thyroxine overdose: a case report. 7 Toxicol Clin Toxicol 1983;20(5):517-20.

15. Kreisner E, Lutzky M, Gross JL. Charcoal hemoperfusion in the treatment of levothyroxine intoxication. Thyroid 2010;20(2):209-12.

16. Hack JB, Leviss JA, Nelson LS, et al. Severe symptoms following a massive intentional L-thyroxine ingestion. Vet Hum Toxicol 1999;41(5):323-6.

17. Personne M, Persson H, Sjöberg E. Citalopram toxicity. Lancet 1997;350(9076):518-9.

18. Sternlicht J, Wogan JM. Thyroid and adrenal disorders. In: Marx J, Hockberger R, Walls R (eds.), Rosen's emergency medicine: concepts and clinical practice, 7 th ed. New York: Elsevier; 2013.

19. Bouchard N. Thyroid and antithyroid medications. In: Nelson L, Lewin N, Howland M, et al. (eds.), Goldfrank's toxicological emergencies, 9th ed. New York: McGraw-Hill; 2011.

20. Laurberg P, Wallin G, Tallstedt L, et al. TSHreceptor autoimmunity in Graves disease after therapy with anti-thyroid drugs, surgery, or radioiodine: a 5-year prospective randomized study. Eur $\mathcal{F}$ Endocrinol 2008; 158(1):69-75.

21. Burch HB, Wartofsky L. Life-threatening thyrotoxicosis. Thyroid storm. Endocrinol Metab Clin North Am 1993;22(2): 263-77.

22. Jude EB, Dale J, Kumar S, Dodson PM. Treatment of thyrotoxicosis resistant to carbimazole with corticosteroids. Postgrad Med 7 1996;72(850):489-91.

23. Tsai WC, Pei D, Wang TF, et al. The effect of combination therapy with propylthiouracil and cholestyramine in the treatment of Graves' hyperthyroidism. Clin Endocrinol (Oxf) 2005;62(5):521-4.

24. Kaykhaei MA, Shams M, Sadegholvad A, et al. Low doses of cholestyramine in the treatment of hyperthyroidism. Endocrine 2008;34(1-3):52-5.

25. de Luis DA, Duenas A, Martin J, et al. Light symptoms following a high-dose intentional L-thyroxine ingestion treated with cholestyramine. Horm Res 2002;57(1-2): $61-3$. 
26. Laurberg P, Boye N. Inhibitory effect of various radiographic contrast agents on secretion of thyroxine by the dog thyroid and on peripheral and thyroidal deiodination of thyroxine to tri-iodothyronine. $\mathcal{F}$ Endocrinol 1987;112: 387-90.

27. Nayak B, Burman K. Thyrotoxicosis and thyroid storm. Endocrinol Metab Clin North Am 2006;35(4):663-86.

28. Binimelis J, Bassas L, Marruecos L, et al. Massive thyroxine intoxication: evaluation of plasma extraction. Intensive Care Med 1987;13(1):33-8.
29. Henderson A, Hickman P, Ward G, et al. Lack of efficacy of plasmapheresis in a patient overdosed with thyroxine. Anaesth Intensive Care 1994;22(4):463-4.

30. Nakamura H, Miyauchi A, Miyawaki N, et al. Analysis of 754 cases of antithyroid drug-induced agranulocytosis over 30 years in Japan. 7 Clin Endocrinol Metab 2013;98 (12):4776-83.

31. Malozowski S, Chiesa A. Propylthiouracil-induced hepatotoxicity and death. Hopefully, never more. 7 Clin Endocrinol Metab 2010;95(7):3161-3. 